\title{
Bluetooth for Java
}

BRUCE HOPKINS AND RANJITH ANTONY

APress Media, LLC 
Bluetooth for Java

Copyright $\odot 2003$ by Apress

Originally published by Apress in 2003

All rights reserved. No part of this work may be reproduced or transmitted in any form or by any means, electronic or mechanical, including photocopying, recording, or by any information storage or retrieval system, without the prior written permission of the copyright owner and the publisher.

ISBN 978-1-59059-078-2

DOI 10.1007/978-1-4302-0763-4

ISBN 978-1-4302-0763-4 (eBook)

Trademarked names may appear in this book. Rather than use a trademark symbol with every occurrence of a trademarked name, we use the names only in an editorial fashion and to the benefit of the trademark owner, with no intention of infringement of the trademark.

Technical Reviewer: Andrew Stringer

Editorial Directors: Dan Appleman, Gary Cornell, Simon Hayes, Karen Watterson, John Zukowski Assistant Publisher: Grace Wong

Project Manager and Development Editor: Tracy Brown Collins

Copy Editor: Ami Knox

Compositor: Impressions Book and Journal Services, Inc.

Artist and Cover Designer: Kurt Krames

Indexer: Valerie Robbins

Production Manager: Kari Brooks

Manufacturing Manager: Tom Debolski

Distributed to the book trade in the United States by Springer-Verlag New York, Inc., 175 Fifth Avenue, New York, NY, 10010 and outside the United States by Springer-Verlag GmbH \& Co. KG, Tiergartenstr. 17, 69112 Heidelberg, Germany.

In the United States, phone 1-800-SPRINGER, email orders@springer-ny.com, or visit http://www. springer-ny.com.

Outside the United States, fax +496221345229 , email orders@springer. de, or visit

http://www.springer.de.

For information on translations, please contact Apress directly at 2560 9th Street, Suite 219, Berkeley, CA 94710. Phone 510-549-5930, fax: 510-549-5939, email info@apress.com, or visit http://wWw. apress.com.

The information in this book is distributed on an "as is" basis, without warranty. Although every precaution has been taken in the preparation of this work, neither the author nor Apress shall have any liability to any person or entity with respect to any loss or damage caused or alleged to be caused directly or indirectly by the information contained in this work.

The source code for this book is available to readers at http://www. apress. com in the Downloads section. 
First and foremost, I dedicate this book to the Lord Jesus Christ, without whom I could not have written this book. I also dedicate this book to my loving wife, Schrell, and my two wonderful children, Lydia and Bruce Jr. -Bruce Hopkins

Dedicated to my parents, Prof. Antony Mampilly and Prof. Kochurani Mampilly. -Ranjith Antony 


\section{Contents at a Glance}

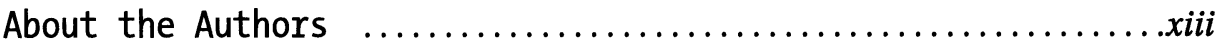

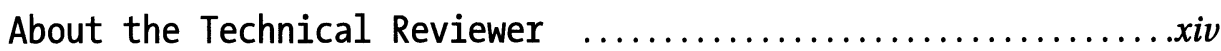

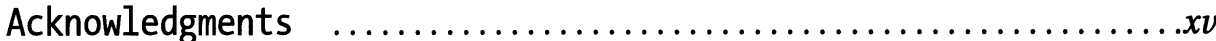

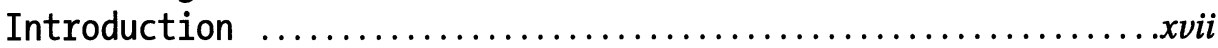

Chapter 1 Introducing Bluetooth $\ldots \ldots \ldots \ldots \ldots \ldots \ldots \ldots \ldots \ldots$

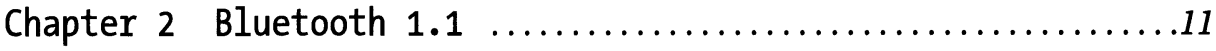

Chapter 3 Before You Get Started $\ldots \ldots \ldots \ldots \ldots \ldots \ldots \ldots \ldots \ldots . \ldots \ldots$

Chapter 4 Understanding the Java Bluetooth API $\ldots \ldots \ldots \ldots . . .45$

Chapter 5 Bluetooth with J2ME MIDP $\ldots \ldots \ldots \ldots \ldots \ldots \ldots \ldots \ldots . \ldots \ldots$

Chapter 6 Creating a Bluetooth Print Server

with JPS API $\ldots \ldots \ldots \ldots \ldots \ldots \ldots \ldots \ldots \ldots \ldots . \ldots . \ldots \ldots$

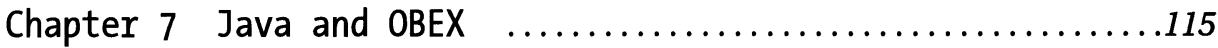

Chapter 8 Using a Bluetooth Simulator ...................137

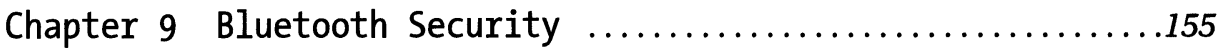

Chapter 10 Wireless Embedded Systems with

the Micro BlueTarget .........................179

Chapter 11 Enterprise Bluetooth Applications with

the Ericsson BlipNet .......................225

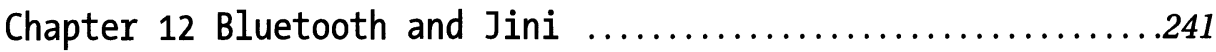




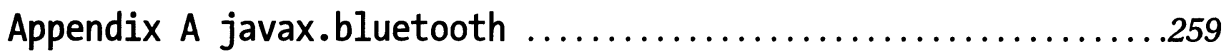

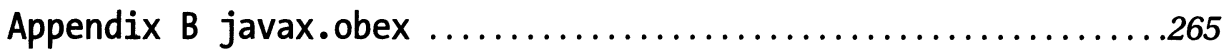

Appendix C Java Bluetooth Development on

the Palm0S Platform $\ldots \ldots \ldots \ldots \ldots \ldots \ldots \ldots \ldots . \ldots \ldots 9 . \ldots \ldots$

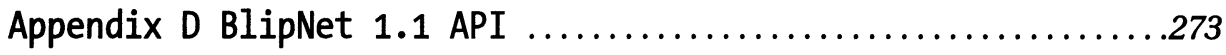

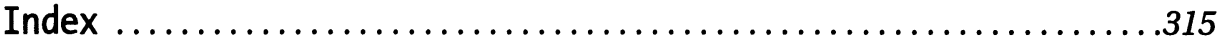




\section{Contents}

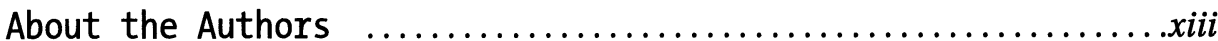

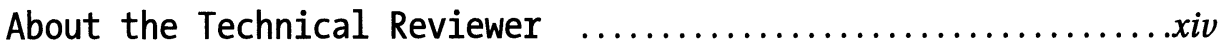

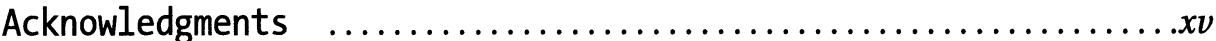

Introduction ...............................................

Chapter 1 Introducing Bluetooth $\ldots \ldots \ldots \ldots \ldots \ldots \ldots \ldots$

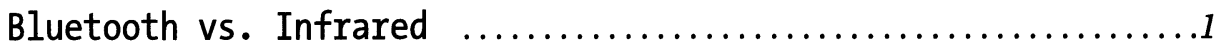

Bluetooth vs. 802.11b ..................................

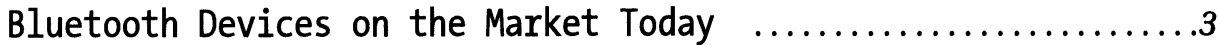

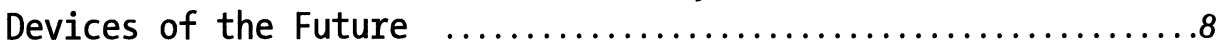

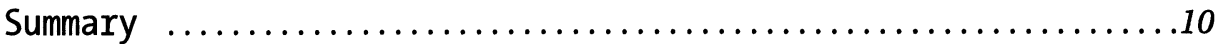

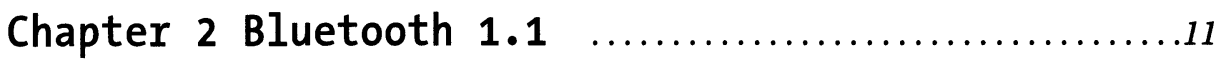

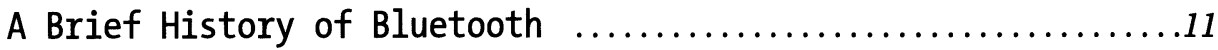

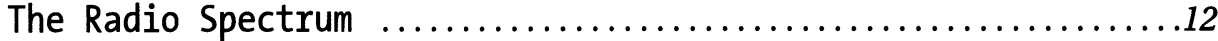

The Bluetooth Protocol Stack ..............................17

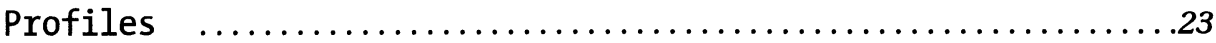

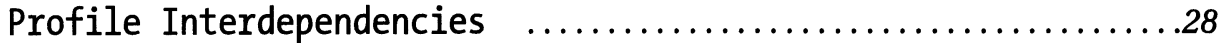

Personal Area Networks: Piconets and Scatternets ............30

The Bluetooth Qualification Process .......................31

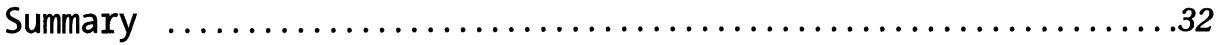

Chapter 3 Before You Get Started ....................33

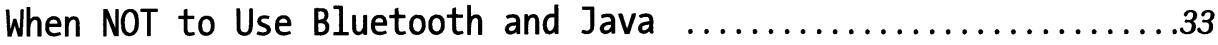

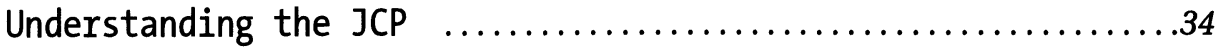

The Benefits of the Java Bluetooth API $\ldots \ldots \ldots \ldots \ldots \ldots \ldots . \ldots . \ldots . \ldots . \ldots$

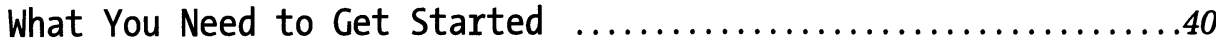

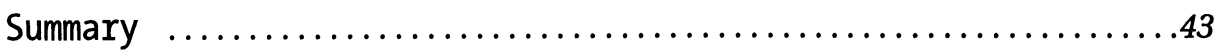


Chapter 4 Understanding the Java

The Basic Components of a Bluetooth Application ...........45

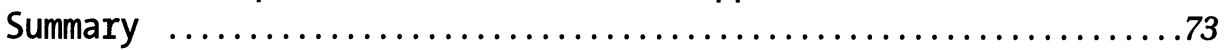

Chapter 5 Bluetooth with J2ME MIDP $\ldots \ldots \ldots \ldots \ldots \ldots$

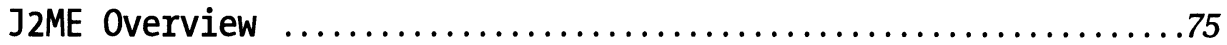

The Mobile Information Device Profile ......................76

Stealth Mode Example ....................................

Piconet Browser Example ................................88

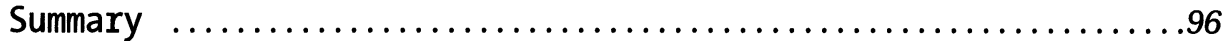

Chapter 6 Creating a Bluetooth Print Server with JPS API

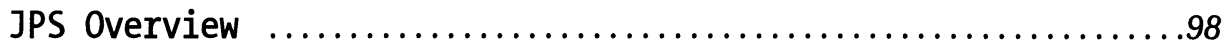

A Step-by-Step JPS Application .........................100

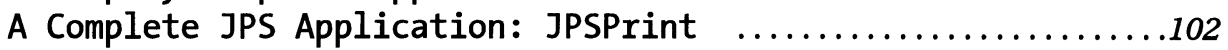

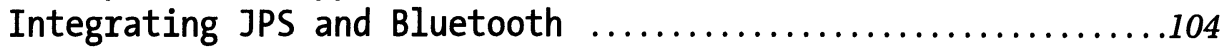

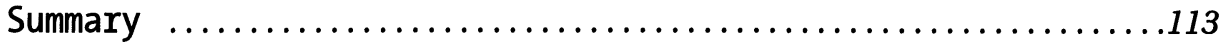

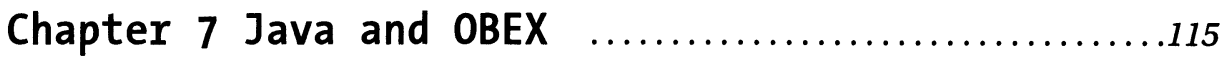

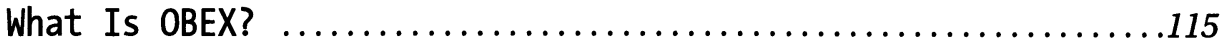

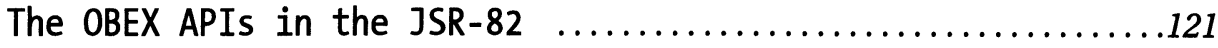

File Transfer Example ................................127

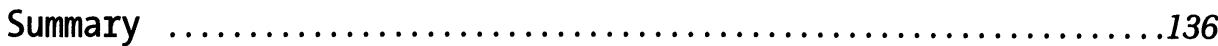

Chapter 8 Using a Bluetooth Simulator ..............137

The Pros and Cons of Using a Simulator $\ldots \ldots \ldots \ldots \ldots \ldots \ldots . \ldots \ldots$

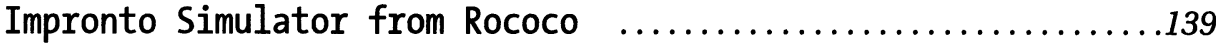

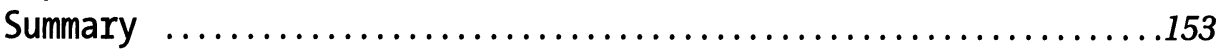


Chapter 9 Bluetooth Security .....................155

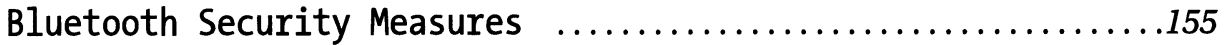

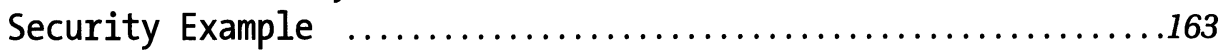

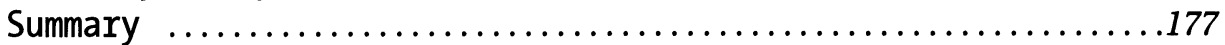

Chapter 10 Wireless Embedded Systems with the Micro BlueTarget ...................179

What Is the Micro BlueTarget? ...........................179

The Micro BlueTarget Hardware Configuration .................182

The Micro BlueTarget Software Configuration ................185

Application Development on the Micro BlueTarget Platform ...187

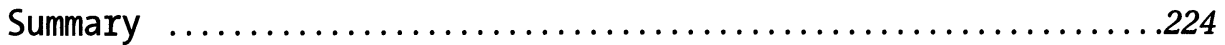

Chapter 11 Enterprise Bluetooth Applications with the Ericsson BlipNet ............225

The Ericsson BlipNet $\ldots \ldots \ldots \ldots \ldots \ldots \ldots \ldots \ldots \ldots \ldots \ldots \ldots \ldots \ldots \ldots \ldots . .226$

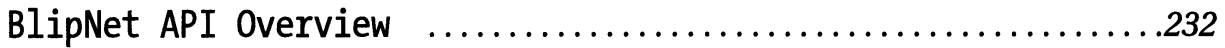

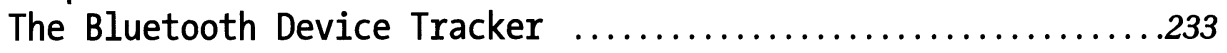

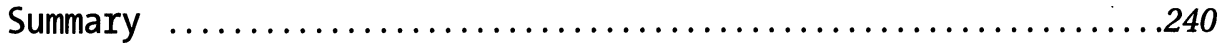

Chapter 12 Bluetooth and Jini $\ldots \ldots \ldots \ldots \ldots \ldots \ldots . \ldots . \ldots . \ldots 1$

What Is Jini Network Technology? .......................242

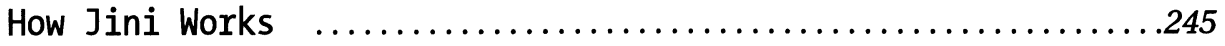

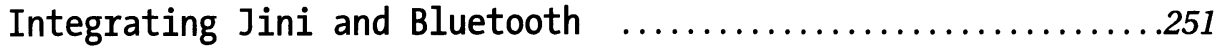

A Jini-Bluetooth-Enabled Device: The PsiNaptic PsiNode .....254

The Benefits of Bluetooth and Jini .......................255

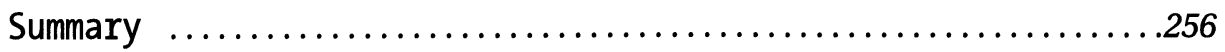

Appendix A javax.bluetooth .......................259

Class BluetoothConnectionException .....................259

Class BluetoothStateException .........................259

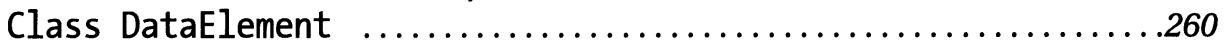




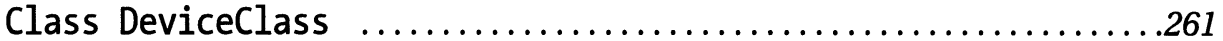

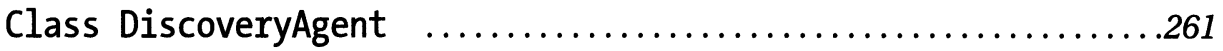

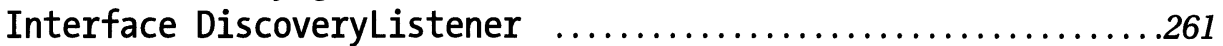

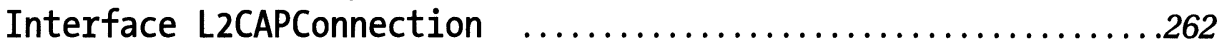

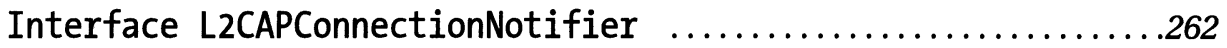

Class LocalDevice ....................................262

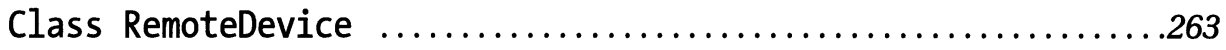

Interface ServiceRecord .................................263

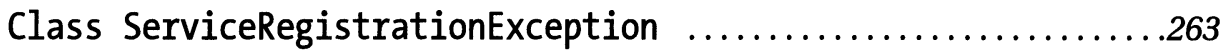

Class UUID ...........................................264

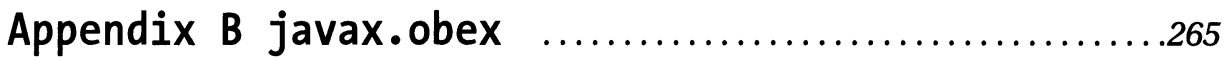

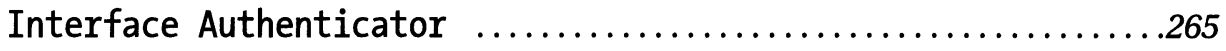

Interface ClientSession ...............................265

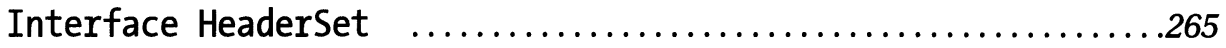

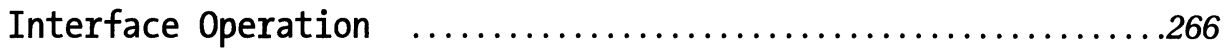

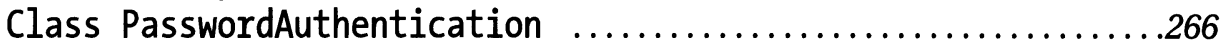

Class ResponseCodes ..................................267

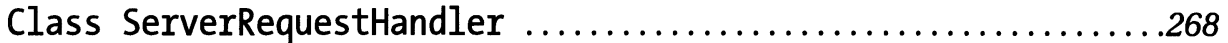

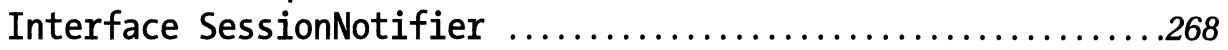

Appendix C Java Bluetooth Development on the Palm0S Platform ....................269

Supported Bluetooth Protocols ...........................269

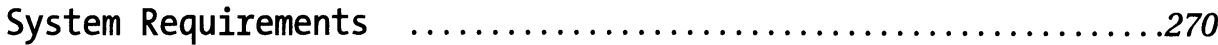

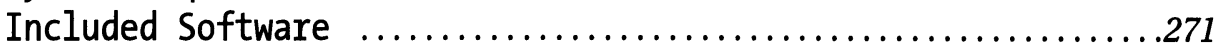

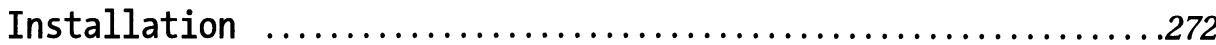

Appendix D BlipNet 1.1 API $\ldots \ldots \ldots \ldots \ldots \ldots \ldots . \ldots . \ldots . \ldots . \ldots . \ldots 273$

Class BlipNetIcons ....................................273

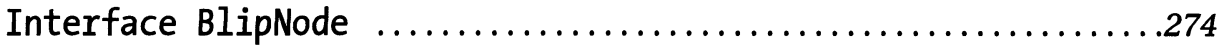

Interface BlipNodeCause .............................275

Interface BlipNodeEvent ..............................277

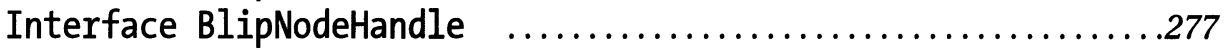

Class BlipNodeHandleInUseException . .....................280

Class BlipNodeHandleReleasedException $\ldots \ldots \ldots \ldots \ldots \ldots \ldots . \ldots . \ldots . \ldots 1$ 
Class BlipNodeNotConnectedException $\ldots \ldots \ldots \ldots \ldots \ldots \ldots \ldots . \ldots . \ldots . \ldots . \ldots 1$

Class BlipServer ....................................281

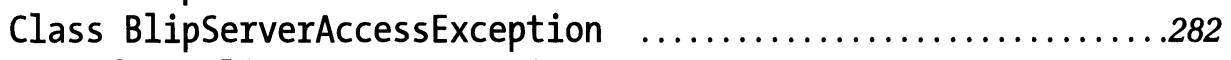

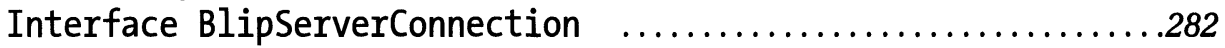

Class BlipServerConnectionException $\ldots \ldots \ldots \ldots \ldots \ldots \ldots \ldots . .284$

Class BlipServerEventAdapter .........................284

Class BlipServerEventFilter ...........................285

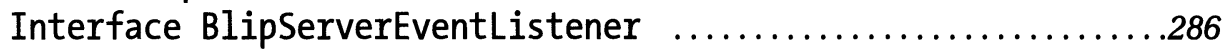

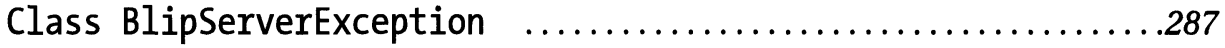

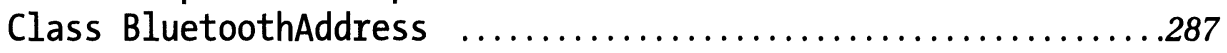

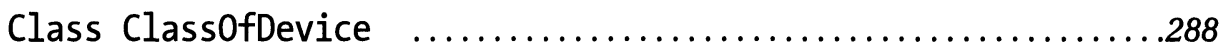

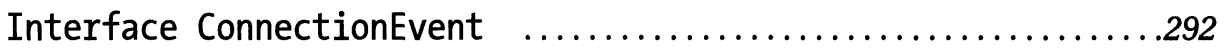

Class EricssonMelody ...............................293

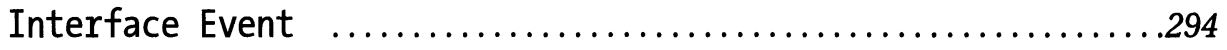

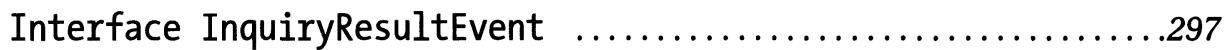

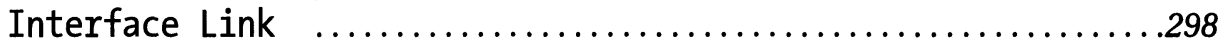

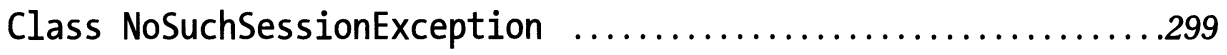

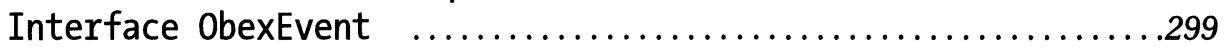

Class ObexFile ........................................

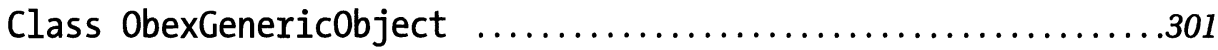

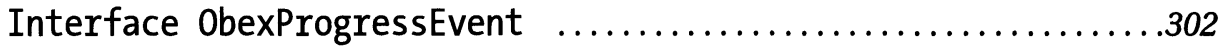

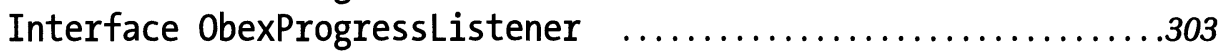

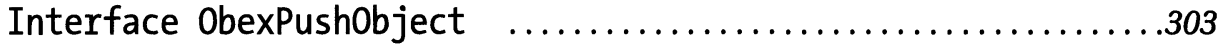

Class ObexServerHostedFile .............................304

Interface PageData ....................................304

Interface RemoteBlipServerEventListener $\ldots \ldots \ldots \ldots \ldots \ldots \ldots . \ldots . \ldots . \ldots 5$

Interface RemoteObexProgressListener $\ldots \ldots \ldots \ldots \ldots \ldots \ldots \ldots . \ldots . \ldots . \ldots . \ldots 5$

Class ScanMode .......................................305

Class Session .........................................307

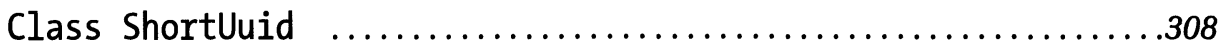

Class TerminalNotConnectedException $\ldots \ldots \ldots \ldots \ldots \ldots \ldots \ldots . \ldots . \ldots . \ldots$

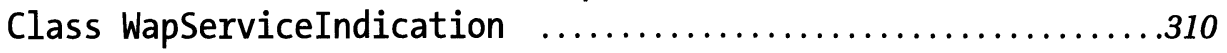

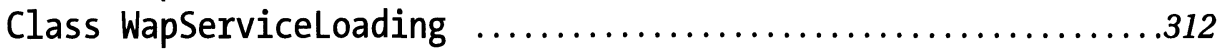

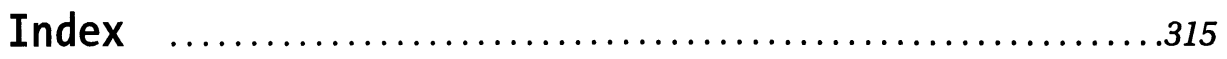




\section{About the Authors}

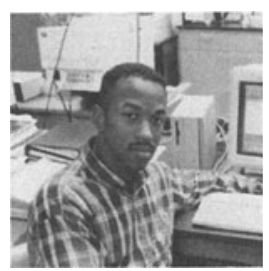

Bruce Hopkins is a 6-year Java veteran with experience in distributed computing and wireless networking. He has an electrical and computer engineering degree from Wayne State University in Detroit and has interest in robotics, microcomputing, and electronics. He has worked in Java since JDK 1.0a, and his research studies include distributed computing, clustering, encryption, and pervasive computing. He currently works as an independent consultant in the Metro Detroit area.

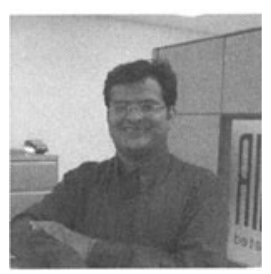

Ranjith Antony earned his bachelor of technology degree in computer engineering from the College of Engineering, Chengannur, Kerala, India, an institute affiliated with Cochin University of Science and Technology. He became a lecturer in the Department of Computer Engineering of the Government Model Engineering College, an institute affiliated with Cochin University of Science and Technology. In June 1998, he joined Atinav as a software engineer. Presently, he is working as a senior technical manager and is managing the Bluetooth-related Java products from Atinav. 


\section{About the Technical Reviewer}

Andrew Stringer was educated at the Dublin Institute of Technology in computer science and software engineering, receiving a bachelor of science degree. Andrew joined Rococo Software in 2001 as a trainer and consultant in the field of wireless software development. Andrew has great experience in developing and delivering courses with J2ME and also with Java APIs for Bluetooth Wireless Technology (JABWT). Andrew lives in Dublin, Ireland. 


\section{Acknowledgments}

I PERSONALIY WANT TO THANK all the people who helped me in writing the book that you're holding. Never in a million years would I have thought that I would be working with Gary Cornell and John Zukowski, both of whom are very respected Java authors. I'm very grateful that Gary and John accepted my proposal way back in January of 2002. For that matter, I want to thank the rest of the team at Apress including Tracy Brown, Ami Knox, Kari Brooks, and Wanshun Tam. More honor, however, goes to Tracy. Many thanks to Andrew Stringer from Rococo for tech reviewing this book; I never knew that I could have been wrong so many times. It's good to have an expert at your disposal.

Bluetooth equipment isn't cheap, so I also want to acknowledge all the great companies around the world (literally) that gave Ranjith and me hardware loans and technical assistance. For instance, Jeff Day and the rest of the team at 3Com (including Ken Morley, Brent Nixon, and Randy Rollins) were very helpful in providing us with Bluetooth adapters and tech support. Mahendra Tailor from TDK Systems in the UK was very helpful in providing us with equipment as well. Rococo was very kind to allow us to have an extended evaluation period in order to write the chapter on Bluetooth simulation. Thanks to Geraldine, Karl, and the rest of the team in Ireland. Lim Siong Huat from Mobiwave in Singapore was very helpful in allowing us to use their protocol analyzer for the security chapter. Peter Duchemin from Smart Network Devices in Germany was very helpful in getting me the inside scoop on their Micro BlueTarget. I also want to thank Niels-Christian Gjerrild from Ericsson in Sweden for hardware and documentation on the Ericsson BlipNet system. North of the border, in Canada, I also received assistance from Dr. Steven Knudsen regarding the integration of Jini and Bluetooth.

This is my first book, so I definitely have to thank all the wonderful teachers at Grant, Cass Tech, and WSU who helped me to get here. You'll never forget a good teacher, and I've had many in my lifetime. I want to thank personally Mrs. Smith, Mrs. Parent, Mr. Walker, and Mrs. Cowan from Grant School. At Cass Tech, I had the pleasure to study under Mr. Miller, Mr. Raymond, and Mrs. Ashford. Dr. Steve Kahn was a little disappointed that I didn't finish my degree with the Mathematics Department after I joined the Emerging Scholars Program, but he deserves to be mentioned. I also want to thank Dr. Chaudhary for giving me the opportunity to study and research with him in the Parallel and Distributed Computing Lab at Wayne State. Very few students were eligible to work in the undergraduate research program, and I'm grateful to Bill Hill for allowing me to be a part of it. 
I wouldn't be the person that I am today without the spiritual guidance of my pastors at Bethlehem Temple Church. Many thanks to the late Bishop Jackson, the late Bishop Porter, Elder Clark, and the whole church family.

I'm the youngest of seven children, so each one of my siblings played a role in shaping my life and career. Thanks to Theresa, Valerie, Darlene, Barbara, Mark, and Tyrone. I definitely have to give special thanks to Mom and Dad, because they've dealt with me for 26 years of my life. They did an excellent job raising all seven children with college educations. Thanks to Thaddeus Johnson for being a good friend. In order to stay smart, you have to hang around smart people.

Finally, I want to thank my wonderfully sweet wife, Schrell. She was very patient and understanding while I wrote this book. She is truly a virtuous woman.

-Bruce Hopkins

Numerous people have provided assistance, advice, and encouragement during the preparation of this book. Major contributors of material, ideas, insights, solutions, and explanations that have found their way into this book include James Jose, Salman Ali, Rajesh Rabindranath, Sudhin Latheef, Vaishali Patil, and Sajith M Nair. Besides them, my teammates at Atinav, especially George Mathew, Cipson Jose, and Dinkar Raj, have contributed suggestions, fixed program bugs, and made imperceptible contributions too numerous to mention. I am also grateful to Mr. Lim Siong Huat and his colleagues at Mobiwave for extending their support by providing timely advice and necessary equipment. Without him, the chapter on Bluetooth security would not have materialized.

-Ranjith Antony 


\section{Introduction}

IN THE NEAR FUTURE, Bluetooth wireless technology will be embedded into nearly every consumer electronics device. Devices like mobile phones, PDAs, laptops, desktops, calculators, watches, keyboards, mice, printers, scanners, cameras, and video game consoles are just a sample of what device manufacturers will be embedding with Bluetooth. Today, Bluetooth chipsets can be purchased (in mass quantities) for $\$ 5$, so it's only a matter of time before many of your personal devices become Bluetooth enabled.

With Java, you get the ability to create applications that are agnostic of their underlying hardware platform. As you can see, this makes Java the perfect programming language for Bluetooth! Regardless of the hardware or OS used for your PDA, mobile phone, watch, etc., you can use the same programming language to create your Bluetooth applications. This book is all about how to create wireless applications using Java and Bluetooth.

\section{How This Book Is Organized}

Here's an overview of what's covered in this book:

Chapter 1: Introducing Bluetooth: If you're completely new to Bluetooth, then this chapter is for you. In Chapter 1, we give a brief introduction to Bluetooth, with a general explanation of what you can do with the technology.

Chapter 2: Bluetooth 1.1: In this chapter, we dive right into the dirty details of the Bluetooth protocol. Here we define the roles and relationships between the Bluetooth stack, Bluetooth profiles, and Bluetooth hardware. If you've seen Bluetooth terminology before, but you don't know the difference between SDP and SDAP for instance, then this chapter will help clear things up.

Chapter 3: Before You Get Started: Chapter 3 is very appropriately named because it covers all the loose ends that need to be addressed before we show you how to integrate Bluetooth and Java.

Chapter 4: Understanding the Java Bluetooth API: This chapter covers the full life cycle of a Bluetooth application (whether you're using Java or not). This chapter also shows you how to use the javax. bluetooth package of 
the official Java Bluetooth API (the JSR-82) in order to create Bluetooth applications.

Chapter 5: Bluetooth with J2ME MIDP: The first complete example of a Java Bluetooth application is explained in Chapter 5. Before we present the code, however, we provide a short review of the J2ME MIDP.

Chapter 6: Creating a Bluetooth Print Server with JPS API: Now with a complete example under your belt, things will start to get pretty exciting. In Chapter 6, we introduce you to the Java Printing API and show you how to create a Bluetooth print server.

Chapter 7: Java and OBEX: Chapter 7 covers the foundation of the OBEX protocol and provides an example on how to transfer files using the javax. obex package of the JSR-82.

Chapter 8: Using a Bluetooth Simulator: As you might have guessed, this chapter is all about how to create Java applications that interact with virtual Bluetooth devices. In this chapter, the entire Bluetooth network is simulated in software.

Chapter 9: Bluetooth Security: Chapter 9 covers the security measures provided by the Bluetooth specification in order to make wireless applications more secure.

Chapter 10: Wireless Embedded Systems with the Micro BlueTarget: The primary focus of Chapter 10 is the Micro BlueTarget by Smart Network Devices. In this chapter, we explore the possibilities of creating applications with a fully functional computer that fits in your hand and includes an implementation of the JSR-82.

Chapter 11: Enterprise Bluetooth Applications with the Ericsson BlipNet: In Chapter 11, we introduce you to enterprise Bluetooth applications and show you how to construct them using Java and the Ericsson BlipNet.

Chapter 12: Bluetooth and Jini: In the final chapter of the book, we provide an overview of Jini network technology and describe how to implement Jini and Bluetooth together.

Appendix A: javax.bluetooth: Appendix A is a handy reference that contains all the method signatures of the javax.bluetooth API. 
Appendix B: javax.obex: Appendix B is a handy reference that contains all the method signatures of the javax. obex API.

Appendix C: Java Bluetooth Development on the PalmOS Platform:

Appendix $\mathrm{C}$ provides a quick overview of how to get started creating Java Bluetooth applications on the Palm OS platform.

Appendix D: BlipNet 1.1 API: Appendix D contains full descriptions of the classes, exceptions, and interfaces that comprise the BlipNet API. This appendix will be really useful to have on hand when developing BlipNet applications.

\section{Intended Audience}

So who are you? This book really has two audiences. If you're a Java developer, then this book assumes that you're an intermediate Java developer with little or no experience with Bluetooth. You'll get the most out of this book if you've written a few Java classes on your own (especially J2ME applications).

If you're a Bluetooth developer, then this book becomes useful to you after Chapter 2. If you've never used Java before, then we'd suggest that you read the first few chapters of a J2ME book before you read this book.

\section{The Code}

The source code for this book is available at http://Www. apress. com in the Downloads section. The book's companion Web site, http://www. javabluetooth.com, also contains the source code, as well as other useful resources such as a list of recommended Bluetooth hardware for running the examples. 